\title{
Mayaro virus: the jungle flu
}

This article was published in the following Dove Press journal:

Virus Adaptation and Treatment

\author{
Ricardo O Izurieta' \\ David A DeLacure' \\ Andres Izurieta ${ }^{2}$ \\ Ismael A Hoare' \\ Miguel Reina Ortiz',3 \\ 'Department of Global Health, \\ College of Public Health, University \\ of South Florida, Tampa, FL, USA; \\ ${ }^{2}$ Department of Computer Science \\ and Engineering, College of \\ Engineering, University of South \\ Florida, Tampa, FL, USA; ${ }^{3}$ Fundación \\ Raíces, Esmeraldas, Ecuador
}

Correspondence: Ricardo O Izurieta Department of Global Health, University of South Florida, I320I Bruce B Downs Blvd, MDC 056, Tampa, FL 336I2, USA Email rizuriet@health.usf.edu

\begin{abstract}
Mayaro fever is an emerging acute viral disease endemic in Central and South America. Mayaro virus (MAYV) is classified in the Semliki Forest virus antigenic complex and shares similarities with the alphavirus Chikungunya virus and the flavivirus Dengue virus. MAYV is an arbovirus transmitted by Haemagogus janthinomys, with competence also demonstrated in Aedes aegypti, Aedes scapularis, and Anopheles quadrimaculatus. Outbreaks and small epidemics of Mayaro fever have occurred in several countries in northern South America and the Caribbean. In addition, travel-associated cases have been reported in European nationals returning from endemic areas. Clinical features of Mayaro fever include fever, chills, persistent arthralgia, retro-orbital pain, maculopapular rash, itching, dizziness, and, rarely, lymphadenopathy. Methods of control for MAYV are similar to those used for other sylvatic arboviruses. Although MAYV was discovered as long ago as the 1950s and continues to be prevalent in the tropical areas of the Americas, it remains neglected and under-studied. This paper provides a thorough and current review of the published MAYV literature ranging from its original description to modern outbreaks, and from the basic virus characteristics to the clinical and epidemiological aspects of this disease.
\end{abstract}

Keywords: Mayaro virus, emerging arbovirus, dengue-like virus, arthrogenic virus

\section{An emerging threat to public health in the Americas}

Mayaro virus (MAYV) is an alphavirus first described in Trinidad and Tobago, and has commonly been reported in South America, Central America, and the Caribbean. ${ }^{1}$ MAYV has mainly been confined to the tropical and subtropical rainforests of the Americas, where it is maintained as an endozoonosis in which non-human primates (including capuchin monkeys [Sapajus spp.], ${ }^{2}$ howler monkeys [Alouatta caraya ${ }^{2}$ and Alouatta seniculus ${ }^{3}$ ], and marmosets [Callithrix argentata $]^{4}$ ) either are main reservoirs or have been reported to have antibodies against MAYV. MAYV is the etiological agent of Mayaro fever, also known as Mayaro virus disease. ${ }^{5}$ However, Mayaro fever has also been imported to Europe, as travelers return home from endemic areas. ${ }^{6}$ Considering that MAYV has been co-isolated along with yellow fever virus from the same invertebrate ${ }^{4,7,8}$ and that Aedes spp. have been reported to be able to transmit MAYV in certain laboratory conditions, ${ }^{9,10}$ the urbanization of MAYV is likely and it has the potential to represent a real threat to the region of the Americas, especially if viral changes lead to more effective transmission by anthropophilic, urban mosquitoes. ${ }^{5}$ 
Although the number of reported Mayaro fever cases and outbreaks is low compared to other arboviruses, it is possible that considerable misdiagnosis and underreporting might lead to inaccurate estimates of Mayaro's public health burden. Accurate diagnosis of Mayaro fever may be complicated by its clinical similarity to other endemic arboviruses such as eastern equine encephalitis virus, Chikungunya virus, Dengue virus, Oropuche virus, yellow fever virus, and Zika virus. ${ }^{511-15}$ In addition, co-infection with Dengue virus has previously been described. ${ }^{15}$ Moreover, immune cross-reactivity with either other Semliki complex viruses in hemagglutinin inhibition and complement fixation assays ${ }^{16}$ or other alphaviruses such as Chikungunya virus in antibody assays (i.e. enzyme-linked immunosorbent assays [ELISAs]) ${ }^{17}$ may pose a diagnostic challenge.

The possibility of MAYV expanding its host and vector range represents an additional concern regarding its potential as an emergent threat to public health in the Americas. Molecular epidemiology surveillance in South and Central America suggests that recent recombination events confirmed the preference of MAYV for human hosts over non-human primates with no effect on MAYV adaptation to mosquito vectors such as Aedes aegypti and Culex quinquefasciatus, to which the virus is nonetheless well adapted. ${ }^{1}$ In addition, the emergence of Mayaro fever cases in $\mathrm{Mexico}^{18}$ and Hait ${ }^{15}$ suggests that the virus is expanding its geographical range of activity. Such geographical distribution could pose a threat to south-eastern and south-western US states (including Florida, Louisiana, Georgia, Alabama, Texas, and California), areas well within the estimated range of aedine mosquitoes. ${ }^{19}$ In fact, Aedes spp. have been detected in these southern state ${ }^{20-22}$ With this mosquito as their vector, will Dengue, Chikungunya, and Zika continue their rampant spread across the continent? Will yellow fever and Mayaro be the new plagues? ${ }^{23}$

Although MAYV was discovered in the tropical areas of the Americas in the 1950s, ${ }^{5}$ it remains neglected and understudied. In addition, owing to the relatively poorly understood nature of MAYV, there is a need to conduct more in-depth research and to employ proven control methods that have worked for other arboviruses to prevent epidemics of MAYV.

\section{History of Mayaro fever, the jungle flu}

In the Amazonian rainforest, Mayaro fever is commonly known as the "jungle flu." This virus was first isolated in 1954 among five febrile patients from the island of Trinidad. ${ }^{24}$ Casals and Whitman characterized MAYV as an arbovirus closely related to the Semliki Forest virus, ${ }^{25}$ which was later confirmed by Lavergne et al. ${ }^{26}$ Circulating MAYV among humans, vertebrate reservoirs, and non-vertebrate vectors has been reported in Suriname, ${ }^{25,27}$ Brazil, ${ }^{28,29}$ Panama, ${ }^{30}$ Trinidad and Tobago, ${ }^{25}$ Bolivia, ${ }^{6}$ Ecuador, ${ }^{7}$ and Venezuela. ${ }^{31}$ In addition, anti-MAYV antibodies have been reported among indigenous populations of Bolivia, Brazil, Colombia, Panama, Peru, Suriname, Trinidad and Tobago, Venezuela, French Guiana, and Mexico. ${ }^{32-35}$ MAYV has also been imported into non-endemic areas including France (from French Guiana, ${ }^{36}$ and Brazi ${ }^{37}$ ), Germany (from Bolivia, ${ }^{6,38}$ French Guiana, ${ }^{39}$ and Ecuador ${ }^{38}$ ), The Netherlands (from Suriname ${ }^{17}$ and Brazil $^{40}$ ), and Switzerland (from Peru ${ }^{41}$ ). In addition, Mayaro infection has been frequently identified among colonists of the Trans-Amazonian Highway in South America. ${ }^{42}$

MAYV outbreaks were reported in the Amazonian rainforest of Belterra, Brazil, in 1978. ${ }^{43}$ The attack rate of MAYV among immunologically virgin populations has been described in outbreaks among Okinawan settlers in Bolivia $^{44}$ and in Dutch military troops in Suriname. ${ }^{27}$ The reported attack rate among Dutch soldiers was 5.3 per 100 person/years at risk. ${ }^{27} \mathrm{MAYV}$ is an important arbovirus in the Amazonian area of French Guiana, with a seroprevalence of $6.3 \%$ among humans and $66 \%$ among non-human primates. ${ }^{3}$ MAYV was first reported in the Amazonian rainforest of Ecuador during the investigation of yellow fever outbreaks in 1997. ${ }^{7}$ The syndrome with fever, rash, and severe arthralgias is described by Amazonian native populations as the "jungle flu."

As mentioned earlier, MAYV has been geographically restricted to Central and South America, with a few cases occurring in the Caribbean. Infrequent outbreaks have occurred in Trinidad, ${ }^{25}$ Brazil, ${ }^{28,29}$ Ecuador, ${ }^{7}$ and Venezuela. ${ }^{31}$ In addition, sporadic cases have been identified in Bolivia, ${ }^{44}$ Haiti, ${ }^{15}$ Mexico,${ }^{18}$ and Peru. ${ }^{45}$ Finally, a few reports of import/ export events exist; these have been summarized in the Epidemiology section.

\section{Characteristics of the virus}

MAYV is an enveloped positive-sense single-stranded RNA virus belonging to the genus Alphavirus in the family Togaviridae. ${ }^{5,46}$ This virus belongs to the Semliki Forest virus antigenic complex, which includes both Old World and New World alphaviruses, including Chikungunya virus, another arbovirus causing similar symptoms. ${ }^{24,46}$ The virus encodes four non-structural proteins, dubbed nsP1-nsP4, and five structural proteins, termed C, 6K, E1, E2, and E3 (the last three comprising the viral envelope proteins). ${ }^{31,47}$ 
Lavergne et $\mathrm{al}^{26}$ suggested that MAYV could have an Old World origin, based on their analysis of the El gene (directly upstream of the $3^{\prime}$-poly(A) tail). Three distinct genotypes have been identified so far, designated $\mathrm{D}, \mathrm{L}$, and $\mathrm{N} .{ }^{5,31}$ As of the date of writing this article, genotype L has only been recovered from patients in Brazil, while genotype $\mathrm{D}$ is distributed more broadly in the Central and South American region. ${ }^{5,31}$

Understanding cell entry of a virus is a key step in understanding infection and, ultimately, in creating an intervention to obstruct viral activity. The mechanisms by which prototype alphaviruses (such as Semliki Forest virus) enter human cells have been known since the early 1990s. However, at present, only one study has investigated the specific cell entry mechanisms of MAYV. The virus achieves cell entry via receptor-mediated endocytosis and fusion with an endosomal membrane through a clathrin-coated pit, a mechanism which it shares with the Semliki Forest virus. ${ }^{48}$ This same study revealed an alternative strategy for endocytosis; MAYV has the ability to use a caveolin-coated pit in place of clathrin to reach the endosome. ${ }^{48}$

\section{Clinical signs and symptoms of Mayaro disease}

Mayaro fever is a self-limiting Dengue-like acute viral disease that has not been reported to cause human fatalities, but can cause temporal severe incapacity which may lead to chronic arthralgia and, in some instances, interfere with daily activities even 1 year after symptom onset. ${ }^{45}$ The onset of the disease is abrupt, with fever (usually between $39^{\circ} \mathrm{C}$ and $\left.40.2^{\circ} \mathrm{C}\right),{ }^{43}$ arthralgia, and maculopapular rash. ${ }^{5}$ In most patients with Mayaro disease, acute symptoms usually last for 3-5 days. ${ }^{5,49}$ Less common symptoms may include dizziness, itching, and cervical and inguinal lymphadenopathy. ${ }^{28,41}$

Along with Chikungunya virus, MAYV is the only alphavirus confirmed to be circulating in the Americas that causes arthralgia, while the others cause encephalitis. ${ }^{26}$ In a prospective study of Mayaro fever patients in Peru, 54\% of patients reported residual joint pain in the hand, wrist, elbows, knees, and feet 12 months after the initial onset of illness. ${ }^{45}$ Axial joint pain was rare. ${ }^{45}$

A typical Mayaro fever rash is shown in Figure 1. This patient was diagnosed during the 1997 yellow fever outbreak investigation in the Amazonian rainforest of Ecuador. ${ }^{7}$ The patient presented with fever, rash, headache, and arthralgias. ${ }^{7}$ The diagnosis was confirmed by the presence of MAYVspecific immunoglobulin $\mathrm{M}(\operatorname{IgM})$ antibodies. ${ }^{7}$

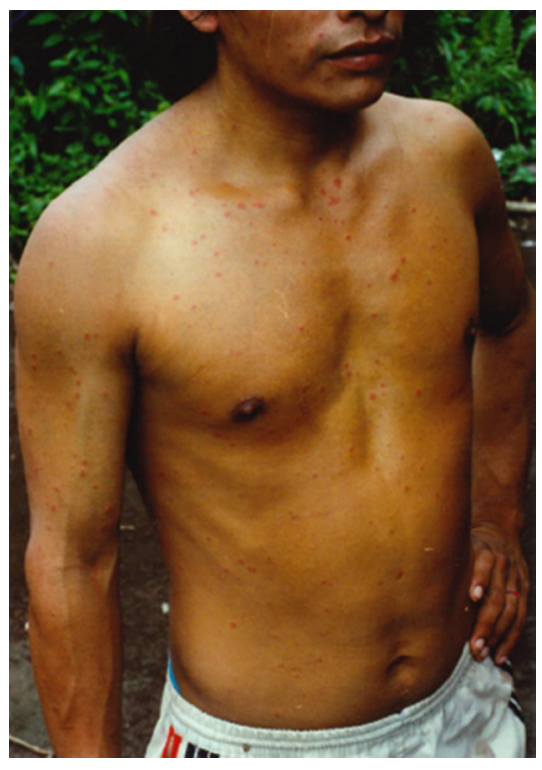

Figure I First laboratory-confirmed case of Mayaro disease in Ecuador. Note: This patient is a native of Montalvo, a community in the Amazonian basin located in Pastaza province.

Clinical signs and symptoms of MAYV are frequently difficult to distinguish from other locally prevalent viruses (both arboviruses and other viruses), bacteria (e.g. leptospirosis), and parasites (e.g. malaria). ${ }^{5}$ While persistent joint pain is most common in patients with alphavirus infections, differential diagnosis should include Chikungunya, Dengue, human herpesvirus-6, parvovirus B-19, rubella virus, and Zika virus. ${ }^{15,28}$ Clinical presumption should be followed by confirmatory laboratory diagnostic techniques including reverse-transcription polymerase chain reaction, indirect immunofluorescence, and virus neutralization assays. ${ }^{15,41} \mathrm{In}$ a cross-sectional study of Ecuadorian military personnel, MAYV prevalence was determined by evaluating the presence of immunoglobulin $\mathrm{G}(\mathrm{IgG})$ and $\operatorname{IgM}$ antibodies via ELISA. ${ }^{7}$

\section{Epidemiology}

As mentioned earlier, Mayaro fever outbreaks have been reported most commonly in northern South America and in the Caribbean (Figure 2), in addition to sporadic cases reported in Mexico and the handful of import/export events reported in the literature (Table 1). In these regions, Mayaro fever has been found to be common in people living in rural areas in close proximity to the forest, especially around the Amazon river basin. ${ }^{49}$ In addition, MAYV may be able to emerge in urban areas, as demonstrated by its ability to be transmitted by Ae. aegypti in a laboratory setting. ${ }^{9,10}$ Should MAYV emerge in urban environments, this would present a 


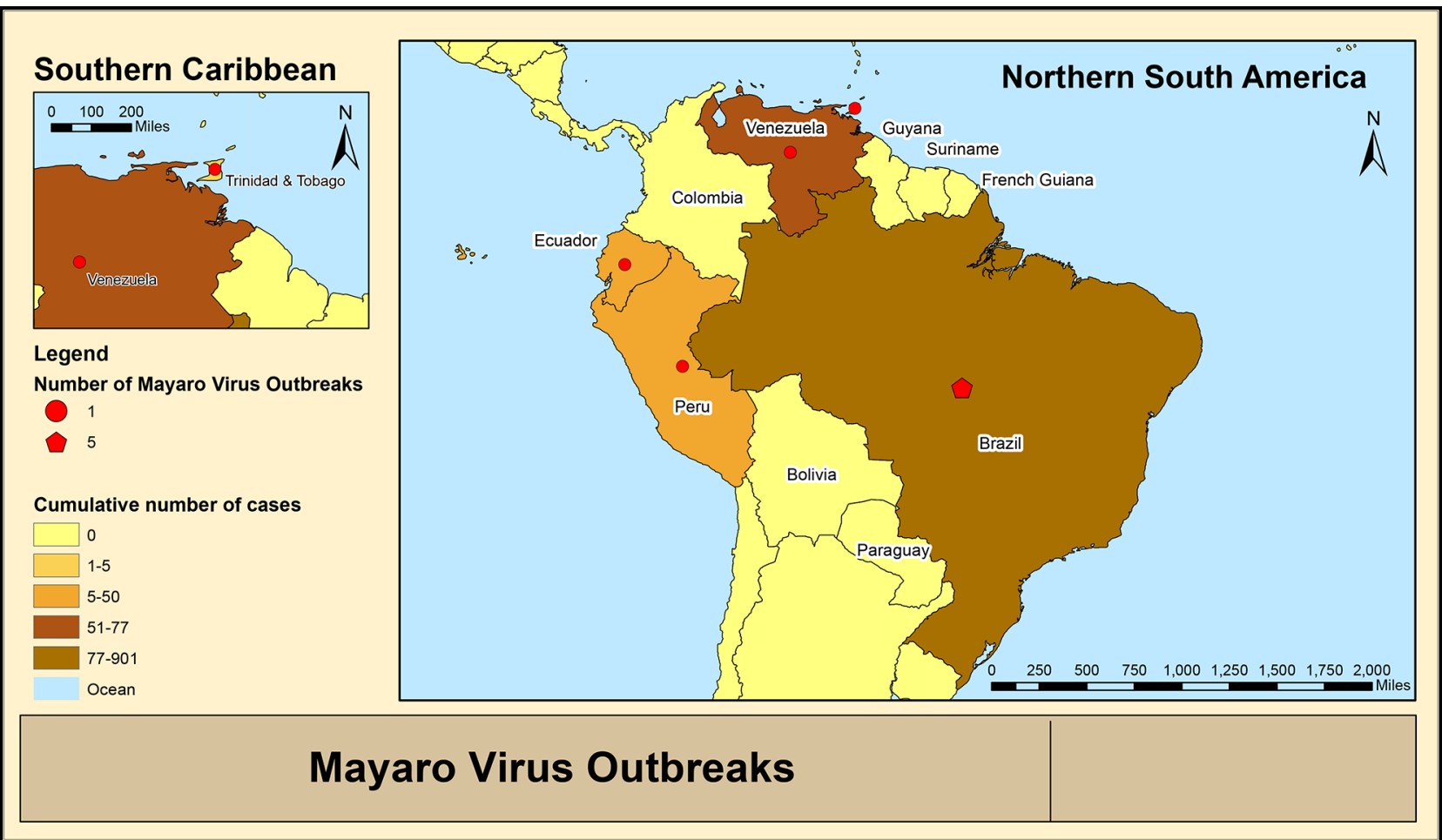

Figure 2 Geographical distribution of Mayaro virus outbreaks.

Note: Data from these studies. ${ }^{7,24,28,31,43,49,51,64,65}$

Table I Mayaro virus fever import/export events by year of event

\begin{tabular}{llll}
\hline $\begin{array}{l}\text { Year of } \\
\text { event }\end{array}$ & $\begin{array}{l}\text { Exporting } \\
\text { country/region }\end{array}$ & $\begin{array}{l}\text { Importing } \\
\text { country }\end{array}$ & Reference \\
\hline 1996 & Peru & USA & 49 \\
1997 & Peru & USA & 49 \\
2008 & Suriname & The Netherlands & 17 \\
2010 & Brazil & France & 37 \\
2011 & Peru & Switzerland & 41 \\
2012 & Bolivia & Germany & 6 \\
2013 & French Guiana & Germany & 39 \\
2013 & Brazil & The Netherlands & 40 \\
2014 & Bolivia & Germany & 38 \\
2014 & Ecuador & Germany & 38 \\
2015 & French Guiana & France & 36 \\
\hline
\end{tabular}

significant threat to public health. ${ }^{5}$ Since MAYV is endemic in areas of the world where Dengue and/or yellow fever virus circulate, and Dengue often produces large-scale urban epidemics, this may lead clinicians to suspect Dengue instead of MAYV fever, possibly contributing to misdiagnosis. Moreover, co-infection and immune cross-reactivity (as discussed in the section "An emerging threat to public health in the Americas"), may also contribute to misdiagnosis and underreporting of MAYV, leading to Mayaro fever's true public health impact being misestimated.
Earlier reports have shown that MAYV has been detected in São Paulo (among three people who visited the forested state of Mato Grosso do Sul ${ }^{28,50}$ and Manaus, ${ }^{51}$ two important cities of the coastal and Amazonian regions of Brazil, respectively. Similarly, people living in the Amazon basin in Ecuador were 23 times more likely to contract an infection by MAYV than people in other regions of the country. ${ }^{7}$ In the same study, $46 \%$ of people living in the Amazon basin in Ecuador had IgM- or IgG-specific antibodies to MAYV, compared with only $2 \%$ of people residing in other regions of Ecuador. ${ }^{7}$ These findings support the notion that people living near the rainforest or those whose occupations require them to work near the rainforest are more likely to be exposed to MAYV mosquito vectors; this can be thought of as a sylvatic cycle of transmission similar to those observed for other arboviruses such as Dengue or yellow fever. ${ }^{5}$

The transmission cycle of MAYV is complex. Although the main mosquito vector for MAYV has been identified (i.e. Haemagogus spp.), ${ }^{52}$ some studies suggest that Ae. aegypti, ${ }^{9,10,52}$ an important urban vector, would be able to transmit the virus. Additional studies exploring the competence of other mosquito species to transmit the virus are needed. Similarly, since other arboviruses (specifically flaviviruses) have demonstrated the ability to persist in 
bodily fluids and transmit sexually, ${ }^{53}$ future studies should investigate other possible routes of transmission for MAYV, along with persistence in bodily fluids, especially synovial liquid. With extensive future studies examining key factors in MAYV infection, we may have a unique opportunity to intervene before this emerging virus becomes a more serious threat to public health.

\section{Seroprevalence of antibodies against MAYV}

The presence of antibodies against MAYV in humans provides epidemiological evidence of its transmission in the Americas. An investigation in Valença, Bahia, in the coastal area of Brazil, reported that only one subject (who had a previous residence of 3 years in the Amazonian rainforest) among 288 sampled individuals had antibodies against Mayaro. ${ }^{54}$ This subject reported that during his residence in the Amazonian rainforest, he had developed a febrile disease with exanthema and arthralgias. ${ }^{54}$ Serological surveys of other populations in northern South America have found antibodies against MAYV in rates that range from $1 \%$ to $60 \%{ }^{44,55}$ A study carried out in Belterra, Brazil, between 1977 and 1978 showed that $10.3 \%$ of the 161 people tested had antibodies against MAYV. No sampling frame was described in selecting subjects for study. In a parallel study conducted by the same team in 1978, during the peak of the MAYV outbreak, 327 people were tested. The sample represented all ages of susceptible people and all residential areas. Seventyone $(22 \%)$ were found to have MAYV antibodies. ${ }^{56}$ During the Belterra outbreak, five fatal cases and one non-fatal case of yellow fever were reported between January and April 1978. In the parallel seroepidemiological survey, 11 people $(3.3 \%)$ had antibodies against yellow fever. Four of these 11 subjects (36\%) reported having had an acute febrile episode during the preceding 2 months. ${ }^{56}$ Thus, in the subsequent study, the prevalence of MAYV exposure rose to $30 \%$ in the autochthonous population. One observation of this study, which is similar to the findings of the 1954 study in Trinidad and Tobago, ${ }^{24}$ is the strong association of MAYV and yellow fever virus. This finding, in addition to the fact that yellow fever, similarly to MAYV, is associated with Haemagogus spp. mosquitoes ${ }^{57}$ and Alouatta spp. monkeys, ${ }^{57}$ supports the assumption that these diseases have similar transmission cycles in the rainforest.

A study using blood bank sera to test for antibodies against MAYV by hemagglutinin inhibition was conducted in French Guiana in $1996 .{ }^{3}$ A total of 1962 sera samples were tested from 896 women and 1066 men. ${ }^{3}$ Antibodies against
MAYV were found in $124(6.3 \%)$ with no significant differences in the seroprevalence rates between women (5.8\%) and men $(6.8 \%) .{ }^{3}$ However, seroprevalence increased significantly with age: $<10$ years old, $0 \%$; $10-19$ years, $5.5 \% ; 20-29$ years, $5.9 \%$; 30-39 years, $8 \%$; 40-49 years, $13 \%$; and $\geq 50$ years, $20 \%{ }^{3}$ Similar to other studies, ${ }^{7}$ seroprevalence differed according to the place of residence. ${ }^{3}$ The highest rates were found in the areas closest to the Amazonian rainforest along the Maroni and Oyapock Rivers, ${ }^{3}$ echoing the findings by Izurieta et al. ${ }^{7}$ A comparison among ethnic groups found that Noir-Marrons and Amerindians had the highest prevalence after adjusting for age. Differences that appear to be based on ethnicity may be attributable to the geographical place of residence. The increased prevalence among older groups was explained by the authors as a consequence of: 1) older people being more likely than young children to go hunting in the forest and 2) an epidemic that occurred about 10 years ago, with the circulation of MAYV being only sporadic since then In addition, a fairly constant transmission risk with increased cumulative incidence over time may explain the age-specific rates, given the smaller sizes in each age stratum. ${ }^{3}$ The same pattern was observed in monkeys, suggesting that MAYV epidemics may occur from time to time with a low endemicity linked to an endozoonosis. ${ }^{3}$

\section{Ecology of the virus}

Sylvatic vertebrates are the principal reservoirs for MAYV maintaining the zoonosis in the rainforest. ${ }^{5}$ Epizootics and epidemics of the disease occur periodically as the virus is spread. Humans become infected through mosquito bites. Based on the only research conducted during an ongoing outbreak, epidemics seem to begin with the onset of the wet season and end with the onset of the dry season. This correlates with the rise and fall of the mosquito population in the rainforest. ${ }^{56}$

\section{Vectors}

The main mosquito vector for MAYV in its sylvatic cycle of transmission has been identified as Haemagogus janthinomys. ${ }^{5,8}$ Along with Ae. aegypti, H. janthinomys has also been identified as a vector for yellow fever virus. ${ }^{48}$ Because MAYV is still emerging and is likely to develop into a more significant public health concern, it is important to identify other species of mosquito that may also transmit the virus.

Because of its prevalence in urban environments and the existence of several urban centers in countries where Mayaro fever is endemic, Ae. aegypti was an excellent candidate for competence studies. Long et al determined that Ae. aegypti 
is competent in transmitting MAYV at a rate of $70 \%$ in a laboratory setting. ${ }^{9}$ Soon after the initial discovery of MAYV, it was demonstrated that Anopheles quadrimaculatus and Aedes scapularis were also moderately competent in transmitting MAYV, although no further experiments have been conducted to confirm these results. ${ }^{24,58}$ More contemporary studies exploring additional species present in tropical urban environments have not been conducted. MAYV has been isolated from several genera of mosquitoes, including Culex spp., Haemagogus spp., Mansonia spp., Aedes spp., Psorophora spp., and Sabethes spp., with H. janthinomys being considered the main vector. , $^{5,59,60}$

Based on all these observations, we propose a potential three-cycle transmission dynamic for MAYV, similar to the one observed for Dengue and yellow fever, whereby the virus is transmitted in the jungle by Haemagogus spp. in a sylvatic cycle which may then reach urban areas through people living in urban or periurban areas and working in or visiting the forest fringe (intermediate cycle); once in the urban setting, the mosquito could potentially be spread by Ae. aegypti in an urban cycle (Figure 3). We posit that it is likely that these three dynamic transmission cycles occur currently and that MAYV is likely to be currently misdiagnosed as Dengue virus (or another locally transmitted pathogen) given their close clinical and immunological profiles, as discussed earlier (see "Epidemiology").

In 1977 and 1978, the epidemic that occurred in Belterra, Pará, Brazil, was the first to be successfully studied. During the Belterra outbreak in Brazil, H. janthinomys yielded the only positive isolate for both MAYV and yellow fever virus. ${ }^{4}$ This vector is found in abundance in the forest canopy, especially around $1 \mathrm{pm}$, followed by a decline in activity around 4 pm. ${ }^{4}$ At nightfall (6 pm), H. janthinomys activity had ceased. ${ }^{4}$ Approximately 12,000 potential biting vectors were captured in a 1 month trapping that coincided with the peak of a MAYV epidemic. MAYV was recovered from H. janthinomys, Limatus flavisetosus, and Wyeomyia aporonoma. Pooled samples of $H$. janthinomys yielded nine

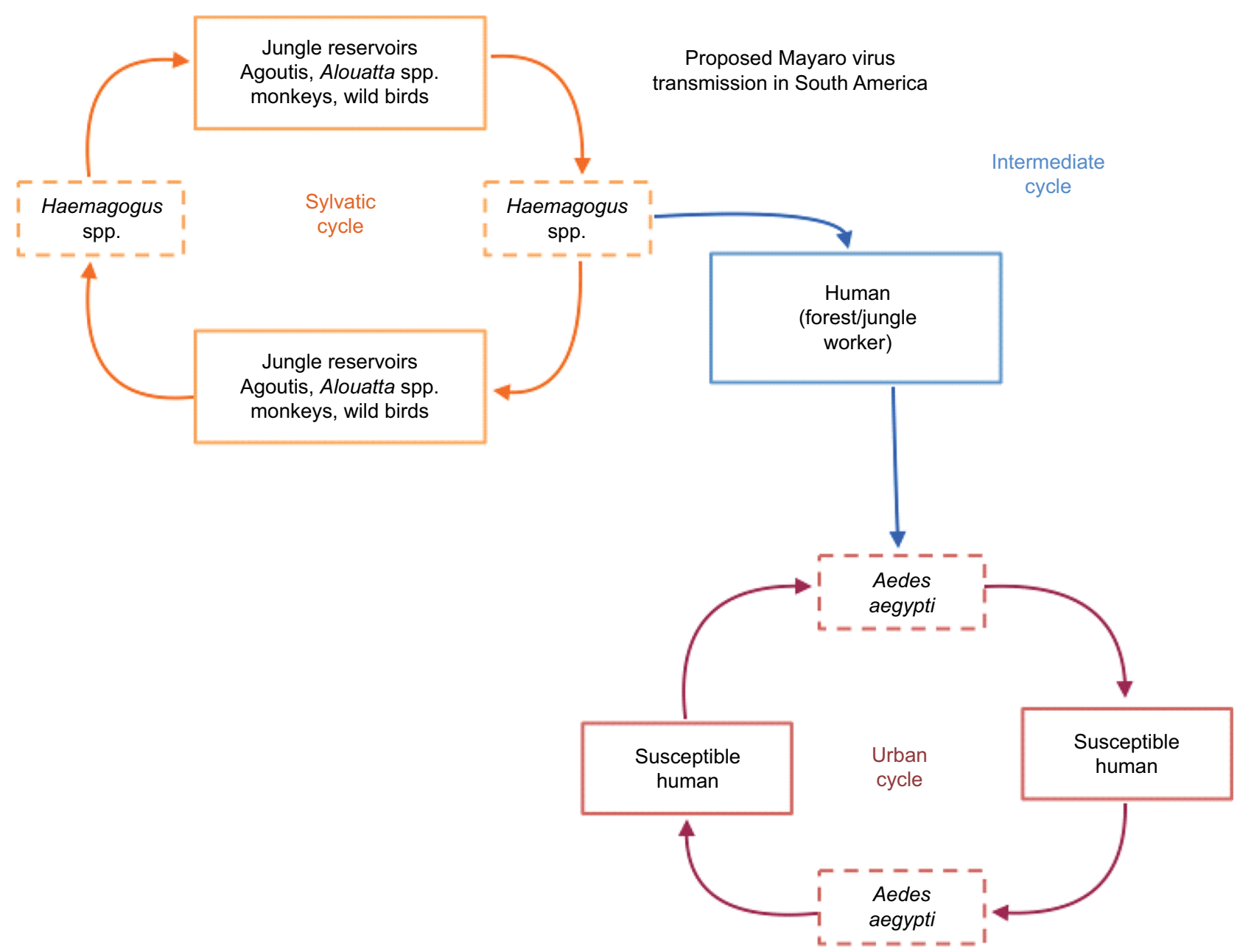

Figure 3 Proposed Mayaro virus transmission cycles for northern South America. Dashed boxes represent mosquito vectors for the virus. 
isolates of MAYV and two isolates of yellow fever virus. The minimum field infection rate of $H$. janthinomys was $1: 82$ for MAYV and 1:368 for yellow fever virus. ${ }^{4}$

\section{Vertebrate reservoirs}

In addition to humans, MAYV infects several species of nonhuman primates and birds. ${ }^{4,61}$ In Panama, agoutis (Dasyprocta punctata) and howler monkeys (Alouatta villosa) have been reported to have antibodies against MAYV. ${ }^{30}$ The median positive titer was $1: 128$ (range 1:32 to $1: 512$ ). ${ }^{30}$ Another finding of that study was that yellow fever antibodies were also detected..$^{30}$ Among the $14 \mathrm{~A}$. villosa primates, nine had antibodies against yellow fever virus. ${ }^{30}$ Based on these findings, the authors concluded that in the Americas, sylvatic yellow fever was a monkey virus. ${ }^{30}$ Seymour et al also hypothesized that MAYV and yellow fever virus may have a similar transmission cycle, based on their finding that antibodies against both viruses were highly prevalent among $A$. villosa.$^{30} \mathrm{MAYV}$ has also been isolated from other vertebrates, including lizards and wild birds. Calisher et al reported the isolation of MAYV in a migrating bird, Icterus spurius, captured in Louisiana in $1967 .^{62}$ The isolation of MAYV in one bird among 1300 studied may suggest that the finding was a rare and incidental infection with no meaning for the transmission of the disease. Nevertheless, the study conducted in Belterra, Brazil, showed a seroprevalence that ranged from $0.4 \%$ to $5 \%$ in seven families of birds. In a previous study, the same authors showed that during 1959 and 1960, 34 out of 119 doves (29\%) in Belém forest, Brazil, had Mayaro antibodies. ${ }^{4}$

Antibodies against MAYV have been detected in the one Cebidae studied and in 32 out of 119 Callitrichidae (27\%). Yellow fever virus was also isolated in the only Cebidae studied and was found in five out of 119 Callitrichidae (4\%). In the same study, two howler monkeys (Alouatta belzebul) were collected during the Mayaro epidemic; however, the test could be performed in only one, which was confirmed positive for yellow fever virus. ${ }^{4}$ In another study, two-thirds of studied howler monkeys (Alouatta seniculus) tested positive for MAYV antibodies. ${ }^{3}$ Gender was not correlated with seroprevalence, but increased age and weight of the monkeys was correlated with increased seroprevalence. The prevalence of MAYV antibodies increased to $84 \%$ in older monkeys. Sera were also collected from 44 tamarins (Saguinus midas), which showed a lower MAYV seroprevalence of $18.2 \%{ }^{3}$

\section{Proposed control methods}

Methods of control are similar to those employed for other arboviruses, particularly for other alphaviruses and flaviviruses. Prevention at its most basic level should consist of the application of insect repellent to repel daytime biters when spending time in endemic areas, especially if working in forested areas. If mosquito density is high, the use of personal nets or long-sleeved shirts and pants may be more appropriate. This prevention strategy should also be employed by people who may have occupational exposure to insect vectors, not simply travelers. In terms of vaccination, two experimental MAYV vaccines are currently being tested in animal experiments and are expected to continue into clinical experimentation. ${ }^{16}$

Epidemiologically, contact tracing and isolation are important control strategies. Contact tracing can be a useful strategy to identify unreported cases of MAYV disease since people living in the same conditions as the patient during the same timeframe are likely to have a similar exposure to the mosquito vector. ${ }^{59}$ In patients who have contracted MAYV fever, reverse isolation (using bed nets and screened rooms to prevent forward transmission) as well as avoiding areas where mosquito vectors are prevalent should be implemented. ${ }^{60}$ Unlike Dengue fever, MAYV fever has not yet produced large-scale urban epidemics. Still, locating and eradicating mosquito vector habitats around human homes should prove useful to obstruct further progression of an epidemic. ${ }^{59,60}$

\section{Disclosure}

The authors report no conflicts of interest in this work.

\section{References}

1. Mavian C, Rife BD, Dollar JJ, et al. Emergence of recombinant Mayaro virus strains from the Amazon basin. Sci Rep. 2017;7(1):8718.

2. Batista PM, Andreotti R, Almeida PS, et al. Detection of arboviruses of public health interest in free-living New World primates (Sapajus spp;; Alouatta caraya) captured in Mato Grosso do Sul, Brazil. Rev Soc Bras Med Trop. 2013;46(6):684-690.

3. Talarmin A, Chandler LJ, Kazanji M, et al. Mayaro virus fever in French Guiana: isolation, identification and seroprevalence. Am J Trop Med Hyg. 1998;59(3):452-456.

4. Hoch AL, Peterson NE, LeDuc JW, Pinheiro FP. An outbreak of Mayaro virus disease in Belterra, Brazil. III. Entomological and ecological studies. Am J Trop Med Hyg. 1981;30(3):689-698.

5. Mackay IM, Arden KE. Mayaro virus: a forest virus primed for a trip to the city? Microbes Infect. 2016;18(12):724-734.

6. Theilacker C, Held J, Allering L, et al. Prolonged polyarthralgia in a German traveller with Mayaro virus infection without inflammatory correlates. BMC Infect Dis. 2013;13:369.

7. Izurieta RO, Macaluso M, Watts DM, et al. Hunting in the rainforest and Mayaro virus infection: an emerging alphavirus in Ecuador. J Glob Infect Dis. 2011;3(4):317-323.

8. Pinheiro FP, LeDuc JW. Mayaro virus disease. In: Monath TP, editor. The Arboviruses: Epidemiology and Ecology. Vol. 3. Boca Raton, FL: CRC Press; 1988:137-150.

9. Long KC, Ziegler SA, Thangamani S, et al. Experimental transmission of Mayaro virus by Aedes aegypti. Am J Trop Med Hyg. 2011;85(4):750-757. 
10. Smith GC, Francy DB. Laboratory studies of a Brazilian strain of Aedes albopictus as a potential vector of Mayaro and Oropuche viruses. $J$ Am Mosq Control Assoc. 1991;7:89-93.

11. Medina G, Garzaro DJ, Barrios M, Auguste AJ, Weaver SC, Pujol FH. Genetic diversity of Venezuelan alphaviruses and circulation of a Venezuelan equine encephalitis virus subtype IAB strain during an interepizootic period. Am J Trop Med Hyg. 2015;93(1):7-10.

12. Navarro JC, Carrera JP, Liria J, Auguste AJ, Weaber SC. Alphaviruses in Latin America and the introduction of Chikungunya virus. In: Ludert J, Pujol F, Arbiza J, editors. Human Virology in Latin America: From Biology to Control. Cham: Springer International Publishing; 2017: 169-192.

13. Izurieta RO, Macaluso M, Watts DM, et al. Assessing yellow fever risk in the Ecuadorian Amazon. J Glob Infect Dis. 2009;1(1):7-13.

14. Alva-Urcia C, Aguilar-Luis MA, Palomares-Reyes C, et al. Emerging and reemerging arboviruses: a new threat in Eastern Peru. PLoS One. 2017;12(11):e0187897.

15. Lednicky J, De Rochars VM, Elbadry M, et al. Mayaro virus in child with acute febrile illness, Haiti, 2015. Emerg Infect Dis. 2016;22(11):2000-2002.

16. Esposito DLA, Fonseca BALD. Will Mayaro virus be responsible for the next outbreak of an arthropod-borne virus in Brazil? Braz J Infect Dis. 2017;21(5):540-544.

17. Hassing RJ, Leparc-Goffart I, Blank SN, et al. Imported Mayaro virus infection in the Netherlands. J Infect. 2010;61(4):343-345.

18. Navarrete-Espinosa J, Gómez-Dantés H. [Arbovirus causing hemorrhagic fever at IMSS]. Rev Med Inst Mex Seguro Soc. 2006;44(4): 347-353.

19. Moskosky SB. Pregnancy intention - more important than ever. Public Health Rep. 2016;131(5):658-660.

20. Azar SR, Roundy CM, Rossi SL, et al. Differential vector competency of Aedes albopictus populations from the Americas for Zika virus. Am J Trop Med Hyg. 2017;97(2):330-339.

21. Diaz JH. Preparing the United States for Zika virus: pre-emptive vector control and personal protection. Wilderness Environ Med. 2016;27(4):450-457.

22. Martinez D, Murray KO, Reyna M, et al. West Nile virus outbreak in Houston and Harris County, Texas, USA, 2014. Emerg Infect Dis. 2017;23(8):1372-1376.

23. Izurieta R. How well are countries of the Americas dealing with health crises? Latin America Advisor. 2016 Dec 19, p3. Available from: http:// www.thedialogue.org/resources/how-well-are-the-americas-dealingwith-health-issues/. Accessed December 7, 2017.

24. Anderson CR, Downs WG, Wattley GH, Ahin NW, Reese AA. Mayaro virus: a new human disease agent. II. Isolation from blood of patients in Trinidad, B.W.I. Am J Trop Med Hyg. 1957;6(6):1012-1016.

25. Casals J, Whitman L. Mayaro virus: a new human disease agent. I. Relationship to other arbor viruses. Am J Trop Med Hyg. 1957;6(6): 1004-1011.

26. Lavergne A, de Thoisy B, Lacoste V, et al. Mayaro virus: complete nucleotide sequence and phylogenetic relationships with other alphaviruses. Virus Res. 2006;117(2):283-290.

27. Karbaat J, Jonkers AH, Spence L. Arbovirus infections in Dutch military personnel stationed in Surinam: a preliminary study. Trop Geogr Med. 1964;16:370-376.

28. Azevedo RSS, Silva EVP, Carvalho VL, et al. Mayaro fever virus, Brazilian Amazon. Emerg Infect Dis. 2009;15(11):1830-1832.

29. Terzian ACB, Auguste AJ, Vedovello D, et al. Isolation and characterization of Mayaro virus from a human in Acre, Brazil. Am J Trop Med Hyg. 2015;92(2):401-404.

30. Seymour C, Peralta PH, Montgomery GG. Serologic evidence of natural togavirus infections in Panamanian sloths and other vertebrates. Am J Trop Med Hyg. 1983;32(4):854-861.

31. Auguste AJ, Liria J, Forrester NL, et al. Evolutionary and ecological characterization of Mayaro virus strains isolated during an outbreak, Venezuela, 2010. Emerg Infect Dis. 2015;21(10):1742-1750.
32. Rodríguez-Morales AJ, Paniz-Mondolfi AE, Villamil-Gómez WE, Navarro JC. Mayaro, Oropouche and Venezuelan Equine Encephalitis viruses: following in the footsteps of Zika? Travel Med Infect Dis. 2017; $15: 72-73$.

33. Muñoz M, Navarro JC. [Mayaro: a re-emerging arbovirus in Venezuela and Latin America]. Biomedica. 2012;32(2):286-302.

34. Torres JR, Russell KL, Vasquez C, Tesh RB, Salas R, Watts DM. Family cluster of Mayaro fever, Venezuela. Emerg Infect Dis. 2004;10(7):1304-1306.

35. Pinheiro FP, Travassos da Rosa APA. Arboviral zoonoses of Central and South America. In: Beran GW, editor. Viral Zoonoses. 2nd ed. Boca Raton: CRC Press; 1994:201-225.

36. Llagonne-Barets M, Icard V, Leparc-Goffart I, et al. A case of Mayaro virus infection imported from French Guiana. J Clin Virol. 2016;77:66-68.

37. Receveur MC, Grandadam M, Pistone T, Malvy D. Infection with Mayaro virus in a French traveller returning from the Amazon region, Brazil, January, 2010. Euro Surveill. 2010;15(18):pii=19563.

38. Tappe D, Pérez-Girón JV, Just-Nübling G, et al. Sustained elevated cytokine levels during recovery phase of Mayaro virus infection. Emerg Infect Dis. 2016;22(4):750-752.

39. Friedrich-Jänicke B, Emmerich P, Tappe D, Günther S, Cadar D, Schmidt-Chanasit J. Genome analysis of Mayaro virus imported to Germany from French Guiana. Emerg Infect Dis. 2014;20(7): 1255-1257.

40. Slegers CA, Keuter M, Guunther S, Schmidt-Chanasit J, van der Ven AJ, de Mast Q. Persisting arthralgia due to Mayaro virus infection in a traveler from Brazil: is there a risk for attendants to the 2014 FIFA World Cup? J Clin Virol. 2014;60(3):317-319.

41. Neumayr A, Gabriel M, Fritz J, et al. Mayaro virus infection in traveler returning from Amazon Basin, northern Peru. Emerg Infect Dis. 2012;18(4):695-696.

42. Pinheiro FP, Bensabath G, Travassos da Rosa APA, et al. Public health hazards among workers along the Trans-Amazon Highway. J Occup Med. 1977;19(7):490-497.

43. Pinheiro FP, Freitas RB, Travassos da Rosa JF, Gabbay YB, Mello WA, LeDuc JW. An outbreak of Mayaro virus disease in Belterra, Brazil. I. Clinical and virological findings. Am J Trop Med Hyg. 1981;30(3): 674-681.

44. Schaeffer M, Gajdusek DC, Lema AB, Eichenwald H. Epidemic jungle fevers among Okinawan colonists in the Bolivian rain forest. I. Epidemiology. Am J Trop Med Hyg. 1981;8(3):372-396.

45. Halsey ES, Siles C, Guevara C, et al. Mayaro virus infection, Amazon Basin region, Peru, 2010-2013. Emerg Infect Dis. 2013;19(11): $1839-1842$.

46. Strauss JH, Strauss EG. The alphaviruses: gene expression, replication, and evolution. Microbiol Rev. 1994;58(3):491-562. Erratum in Microbiol Rev. 1994;58(4):806.

47. Gould EA, Coutard B, Malet H, et al. Understanding the alphaviruses: recent research on important emerging pathogens and progress towards their control. Antiviral Res. 2010;87(2):111-124.

48. Carvalho CAM, Silva JL, Oliveira AC, Gomes AMO. On the entry of an emerging arbovirus into host cells: Mayaro virus takes the highway to the cytoplasm through fusion with early endosomes and caveolaederived vesicles. PeerJ. 2017;5:e3245.

49. Tesh RB, Watts DM, Russell KL, et al. Mayaro virus disease: an emerging mosquito-borne zoonosis in tropical South America. Clin Infect Dis. 1999;28(1):67-73.

50. Coimbra TL, Santos CL, Suzuki A, et al. Mayaro virus: imported cases of human infection in São Paulo State, Brazil. Rev Inst Med Trop Sao Paulo. 2007;49(4):221-224

51. Mourão MPG, Bastos M de S, de Figuereido RP, et al. Mayaro fever in the city of Manaus, Brazil, 2007-2008. Vector Borne Zoonotic Dis. 2012;12(1):42-46.

52. Hotez PJ, Murray KO. Dengue, West Nile virus, chikungunya, Zikaand now Mayaro? PLoS Negl Trop Dis. 2017;11(8):e0005462. 
53. Magalhaes T, Foy BD, Marques ETA, Ebel GD, Weger-Lucarelli J. Mosquito-borne and sexual transmission of Zika virus: recent developments and future directions. Virus Res. 2017; pii:S0168-1702(17)30381-7. Epub 2017 Jul 11.

54. Tavares-Neto J, Travassos da Roda APA, Vasconcelos PFC, Costa JML, Travassos da Rosa JFS, Marsden PD. Pesquisa de anitcorpos para arbovírus no soro de residentes no povoado de Corte de Pedra, Valença, Bahia. Mem Inst Oswaldo Cruz. 1986;81(4):351-358.

55. Black FL, Hierholzer WJ, Pinheiro FP, et al. Evidence for persistence of infectious agents in isolated human populations. Am J Epidemiol. 1974;100(3):230-250.

56. LeDuc JW, Pinheiro FP, Travassos da Rosa AP. An outbreak of Mayaro virus disease in Belterra, Brazil. II. Epidemiology. Am J Trop Med Hyg 1981;30(3):682-688.
57. Saraiva MGG, Amorim RDS, Moura MAS, et al. Historical analysis of the records of sylvan yellow fever in the state of Amazonas, Brazil, from 1996 to 2009. Rev Soc Bras Med Trop. 2013;46(2):223-226.

58. Aitken THG, Anderson CR. Virus transmission studies with Trinidadian mosquitoes. Part II. Further observations. Am JTrop Med Hyg. 1959;8(1):41-45.

59. Heymann DL. Control of Communicable Diseases Manual. 19th ed. Washington, DC: American Public Health Association; 2008.

60. Heymann DL. Control of Communicable Diseases Manual. 20th ed. Washington, DC: American Public Health Association; 2014.

61. Figueiredo LTM. Emergent arboviruses in Brazil. Rev Soc Bras Med Trop. 2007;40(2):224-229.

62. Calisher CH, Gutiérrez E, Maness KS, Lord RD. Isolation of Mayaro virus from a migrating bird captured in Louisiana in 1967. Bull Pan Am Health Organ. 1974;8(3):243-248.
Virus Adaptation and Treatment

\section{Publish your work in this journal}

Virus Adaptation and Treatment is an international, peer-reviewed open access journal focusing on the study of virology, viral adaptation and the development and use of antiviral drugs and vaccines to achieve improved outcomes in infection control and treatment. The journal welcomes original research, basic science, clinical \& epidemiological studies,

\section{Dovepress}

reviews \& evaluations, expert opinion and commentary, case reports and extended reports. The manuscript management system is completely online and includes a very quick and fair peer-review system, which is all easy to use. Visit http://www.dovepress.com/testimonials.php to read real quotes from published authors.

Submit your manuscript here: http://www.dovepress.com/virus-adaptation-and-treatment-journal 